\title{
Nasogastric Decompression
}

National Cancer Institute

\section{Source}

National Cancer Institute. Nasogastric Decompression. NCI Thesaurus. Code C70910.

Use of nasogastric tubes after abdominal operation intended to hasten the return of bowel function, prevent pulmonary complications, diminish the risk of anastomotic leakage, increase patient comfort and shorten hospital stay. 